\title{
Design And Testing of Electromechanical Actuator for Aerospace Applications
}

\author{
L. Papini (iD *, P. Connor*, C. Patel ${ }^{\dagger}$, L. Empringham*, C. Gerada*, P. Wheeler* \\ ${ }^{*}$ School of Electrical and Electronic Engineering, The University of Nottingham, Nottingham, NG7 2RD, UK. \\ ${ }^{\dagger}$ Ricardo UK Limited, Cambridge, UK. \\ Email: luca.papini@nottingham.ac.uk
}

\begin{abstract}
Electromechanical actuators are gaining interest in the aerospace industry within the More Electrical Aircraft (MEA) architecture. The end-goal of fully electric aircraft includes Electromechanical actuation for flight control systems. The design and testing of a flight control system for helicopter swashplate is presented in this work. The mechanical system is driven by electrical machines and controlled by dedicated power electronics, both of which fit challenging space requirements and environmental conditions. The predicted performances are validated by experimental testing of prototypes.
\end{abstract}

Index Terms-More Electric Aircraft, Fault Tolerant, Permanent Magnet Machine, Electro-mechanical actuator.

\section{INTRODUCTION}

The drive towards green transportation requires the reduction of $C O x$ emissions to fit the worldwide trend in regulations. The electrification of transportation systems has seen an increasing trend in recent decades [1]. Electromechanical systems have been identified as an alternative to the conventional (hydraulic and mechanical) aircraft system technologies for systems relating to pressurisation, de-icing [2], generation and flight control sub-systems [2], [3]. The confidence in longevity through extensive innovation and research for hydraulic systems comes with the downside of high maintenance costs as well as issues related with other issues such as oil degradation. The potential of fly-by-wire concepts are realised when the actuation system is electromechanical. The investigation into electromechanical systems to replace hydraulic actuators is required in order to assess the capability of achieving high efficiency within the volume constraint imposed by the helicopter architecture [4]. The maximising of power-to-weight ratio is targeted to reduce the aircraftlevel energy consumption [5]. Within the research related to More Electric Aircraft (MEA) [1], [6], the application of electromechanical actuators and electrical machines for propulsion system in helicopters have been investigated [4], [7]. Electrical machines for rotor-craft propulsion have been proposed, as well as electrical actuation of flight control surfaces [8]. The HEMAS (Helicopter Electromechanical Actuation System) project has been focusing on the investigation of electromechanical actuation for swash-plate control. Different configurations can be adopted to connect the swashplate to the helicopter structure to enable the degrees of freedom required for full flight control. The configuration of the electromechanical actuator is selected in order to guarantee the maximum reliability and minimum mass [4]. However, the electrical and mechanical components of the actuator have to be designed in order to operate in an unfavourable environment characterised by a wide temperature range, and the presence of dust and water. The multi-physics design approach is identified as the most suitable design process to be applied for such specifications and application [9]. The interaction between the thermal and mechanical aspects with the electromagnetic one is necessary to enable the actuator to operate in safe conditions within the environmental boundaries imposed [10]. The fault tolerant requirements are a critical aspect for aerospace systems, especially for safety critical components. The fault tolerance can be achieved by means of redundancy and through the design of critical components with embedded fault tolerant capabilities. The design, prototyping and testing of the electrical machines and power electronics for the helicopter swash-plate control system were developed in collaboration with Airbus Helicopters and Liebherr is here presented. The mechanical and thermal design aspects are designed to enable safe operation of the system. Prototypes have been manufactured to validate the modelling and testing in the harsh environmental conditions are performed. The predicted performances are benchmarked against the experimental measurement.

\section{THE HEMAS SYSTEM}

The HEMAS system is located in correspondence of the swash-plate of the helicopter. The overall system structure consists of three actuator circumferentially displaced at $120^{\circ}$ [4]. In Fig. 1 the schematic representation of a single electromechanical actuator is presented. The mechanical structure (MRA) of each actuator consist of a central column, which moves linearly, connected to the fixed part of the actuator by means of a ball-screw system. The top of the central column of the MRA is directly connected to the swash-plate. The helicopter structure is instead connected to the bottom fixed part of the MRA which comprises the locating guides for the central column, the gearbox and the mounting points for the electrical machines. The electrical machines dictate the movement and mechanical speed of the actuator system and ultimately the linear position of the actuator to swash-plate connection. The rotary motion of the machines is transferred 


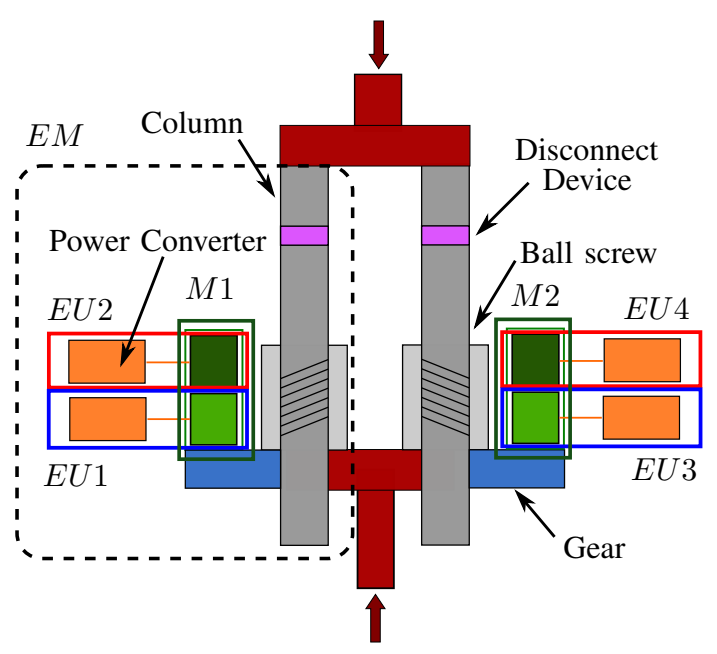

Fig. 1: Electromechanical actuator schematic.

directly from the rotor shaft to the gearbox and through a ball-screw which converts the rotary motion to linear. The challenges in the design of the electrical machines and power electronics are compounded by the requirements for high power density, fault tolerance and careful thermal management. In fact, the HEMAS system is located in the hottest region within the helicopter structure [10]. The helicopter shell limits the air circulation in the actuators location. As liquid cooling would reduce the reliability and increase the system complexity, mass and costs, cooling through natural air convection is used as the primary cooling means. The electrical machines are designed for the worst case ambient temperatures of $T_{a m b}=110\left[{ }^{\circ} \mathrm{C}\right]$ and $T_{a m b}=-30\left[{ }^{\circ} \mathrm{C}\right]$ as the upper and lower bounds, respectively. Natural convective heat transfer between the outer casing of the electrical machines and the external environment is modelled. The limitation of the overall system mass and the fixed space available demand a system optimisation at the design stage [5]. The gear ratio of the mechanical interface between the electrical machine and the mechanical actuator directly impacts on the operating speed of the electrical machine and the mass of the gearbox itself. This subsequently affects the mass of the electrical machines, the thermal management of the components and the specifications for the mechanical coupling. Considering an integrated structure, the single components of the system are modelled to extract for their individual characteristics; the mass of the elements are estimated as well as their thermal behaviour.

Defining each combination of power electronics (PE) and three phase winding set as the basic electrical unit (EU), the single HEMAS actuator consist of $4 \mathrm{EU}$ and $2 \mathrm{EM}$ as depicted in Fig. 1. Each electrical machine (M), featuring double 3-phase winding groups, is dedicated to each EM. The two level control system of the HEMAS is provided by the Swashplate Control Computers (SPCC) and the Actuator Control Electronics (ACE). The SPCC is mainly used for speed and position control of the whole swashplate, while the ACE is assigned to the torque control of the actuators by means of the power converters. The characteristic of the

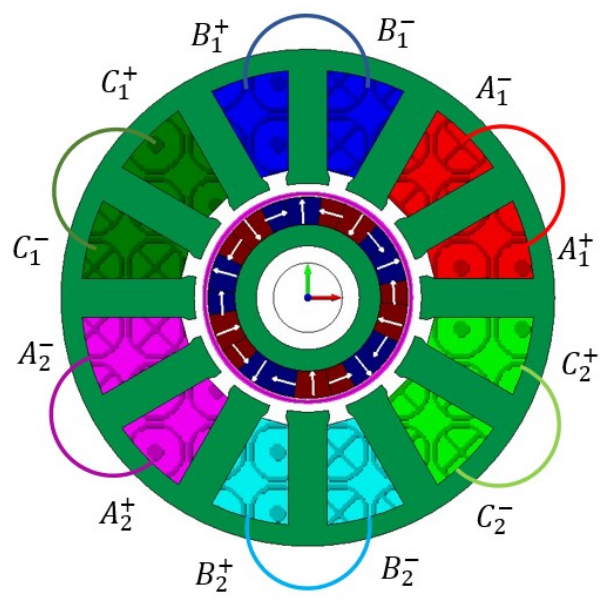

(a) 2D-FE model

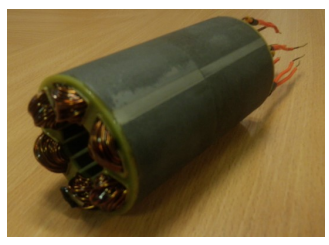

(b) Stator Prototype

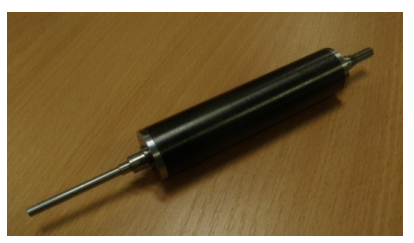

(c) Rotor Prototype
Fig. 2: HEMAS electrical machine: FE model and prototype.

components of each EU, namely the fault tolerant electrical machine and the power electronics are detailed in the following sections.

\section{THE HEMAS ELECTRICAL MACHINES}

Each actuator comprises a mechanical structure driven by two electrical machines (EM). The design of the electrical machines requires a multi-physics approach, according to the above mentioned considerations. A Reluctance Network (RN) modelling approach has been adopted to account for the electromagnetic aspects at the design stage. The thermal aspects have been modelled implementing a thermal resistance network (TRN), which includes for the main dimensions and material characteristics [9]. The temperature limitations for the copper winding structure, the laminations and the permanent magnets are imposed while optimising the geometrical structure of the machine.

\section{A. Electromagnetic Design}

In Fig. 2a the 2D cross-section of the machine modelled in the Finite Element environment is presented. A fractional slotpole structure (10 poles - 12 slots) with concentrated windings is preferred for this application as it results in shorter end windings, high power density and physical phase separation to enhance the reliability against phase-to-phase electrical short circuit [11]. A double three-phase winding arrangement is chosen in order to achieve fault tolerant capabilities through redundancy: the ad-hoc design of the electromagnetic structure to develop minimum breaking torque in balanced three-phase short circuit conditions with short circuit currents limited to 
TABLE I: Electrical motor parameters

\begin{tabular}{ll}
\hline \hline Parameter & \multicolumn{1}{c}{ Value } \\
\hline \multicolumn{2}{c}{ Machine characteristic } \\
Number of 3 -phase unit & 2 \\
Pole pair number & 5 \\
Maximum speed $\omega_{m}$ & $5200[\mathrm{rpm}]$ \\
Rated Current $I_{\text {rated }}$ & $4.7[\mathrm{~A}]$ \\
Peak Current $I_{\text {peak }}$ & $34[\mathrm{~A}]$ \\
Peak Power & $2.6[\mathrm{~kW}]$ \\
Efficiency & $98.8[\%]$ \\
Phase Resistance $R_{s}$ & $0.23[\Omega]$ \\
Phase Inductance $L$ & $1.3[\mathrm{mH}]$ \\
Voltage constant $\kappa_{E}$ & $0.092[\mathrm{~V} / \mathrm{rads}]$ \\
Torque constant $\kappa_{T}$ & $0.142[\mathrm{Nm} / \mathrm{A}]$ \\
\hline \multicolumn{2}{c}{ Geometrical dimension } \\
Inner stator bore & $13.35[\mathrm{~mm}]$ \\
Air-gap thickness & $1.6[\mathrm{~mm}]$ \\
Retaining sleeve thickness & $0.4[\mathrm{~mm}]$ \\
Magnets thickness & $3.2[\mathrm{~mm}]$ \\
\hline
\end{tabular}

the rated value enables operation of the machine after one electrical fault with reduced output power in safe conditions. Circumferential distribution of the two three-phase winding sets is chosen, as shown in Fig .2a., to achieve the highest power density [11]. The prototyped stator structure is presented in Fig. $2 b$.

A Hallbach array ring is selected for the rotor permanent magnet structure. The rotor manufacturing complexity is justified through reduced rotor losses, reduced air-gap magnetic flux density, harmonic content and higher efficiency. A carbon fibre retaining sleeve is designed to encapsulate and retain the Hallbach array structure depicted in Fig. 2c. High performance materials have been selected in order to enhance the power-toweight ratio of the designed structure. A high saturation flux density design for the iron structure is made possible adopting cobalt iron electrical laminations; further enhancement in the power density is achieved by adopting high performance Samarium-Cobalt (Sm-Co) permanent magnets. Conventional copper wire is used for the concentrated winding structure. The system modelling, characteristics and optimisation is detailed in [5] while the main machine dimensions and parameters are reported in TABLE I. The total mass of the prototyped machine results in $2.62[\mathrm{~kg}]$.

\section{B. Mechanical design}

Detailed mechanical design was undertaken for the machine. This included structural calculations, heat-shrink fits, consideration of thermal expansion as well as dynamic issues. Within this paper, the mechanical design relating to torque transmission are detailed. The drive end of the shaft is coupled to the gearbox via a splined connection. The design of the spline at the end of the rotor shaft is performed in order to withstand the torque load requirements of the actuator. The drive end of the shaft is equipped with an involute spline and shear-neck which acts as a mechanical safety feature to protect the gearbox against over-torque. The location of this tailored weak point on the mechanical shaft increase the reliability of the system as mechanical failures would be concentrated onto the shear neck and would results in the decoupling of the electrical motor and the mechanical

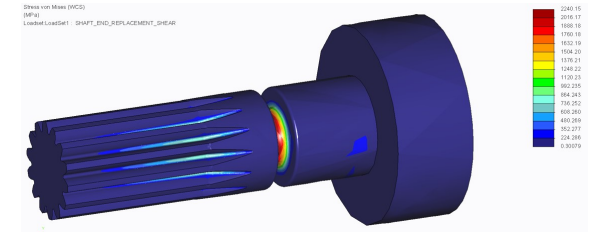

Fig. 3: 3D Finite element stress analysis on the adaptor spline.

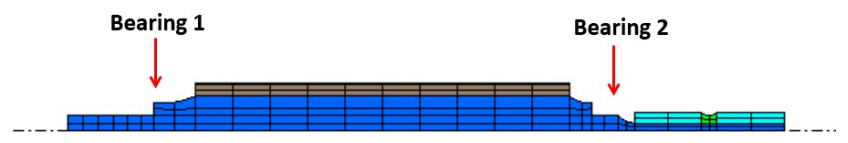

(a) Rotor dynamic Finite element model.

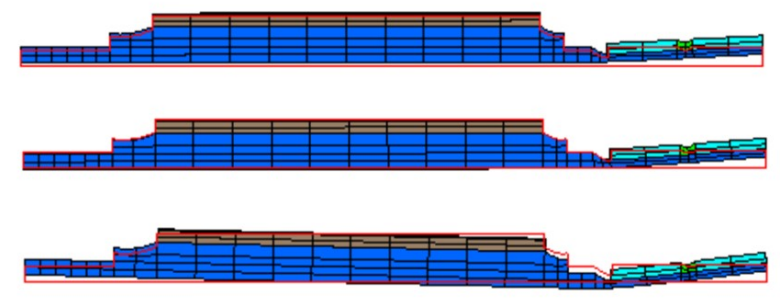

(b) Rotor mode shapes.

Fig. 4: Rotor dynamic analysis: FE model and calculated mode shapes.

actuator. The motor shaft to gearbox interactions and system inertias require careful consideration when designing a shear-neck.

The rotor-dynamic aspects are also considered in order to assess the impact of the non-drive end of the shaft on the mechanical vibrations. A slender, cantilevered shaft at the nondrive end of the machine supports two resolver rotors. The vertical operating conditions of the machines reduce the effect of gravity on the additional resolver masses attached to the shaft. The double resolver arrangement is selected to enhance the reliability of the system. The rotor-dynamic calculations performed focus on the estimation of the natural frequencies and maximum radial tip displacement for the shaft structure supporting the resolvers. Finite Element analysis have been performed on the rotor structure and in Fig. $4 \mathrm{a}$ the model is presented. The rotor critical speed is predicted to be well above the maximum operating speed of the rotor.

\section{The Power Electronics}

The Actuator Control Electronics (ACE) is defined as the power converters and the signal processing part of the system, which is dedicated to operate and control the electrical machines, acquire and transmit to the main control unit the position signal of the central column and monitor the electrical machines operative conditions (electrical fault, winding temperature). The enhancement of the system power density is achieved by means of mass minimisation of the individual components. The ACE unit is designed as a stand-alone system consisting of the FPGA-DSP based process unit and three IGBT three-phase inverters. The DSP unit is dedicate to the 
TABLE II: Rotor Natural Frequencies

\begin{tabular}{ll}
\hline \hline Mode & Frequency $[\mathrm{Hz}]$ \\
\hline 1 & 1045 \\
3 & 1298 \\
5 & 2109 \\
\hline
\end{tabular}

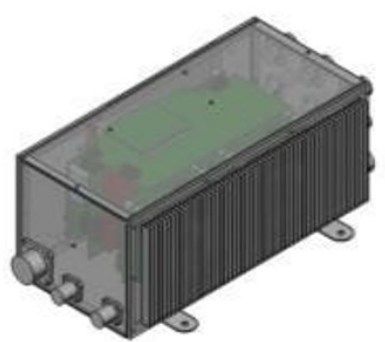

(a) ACE 3D model

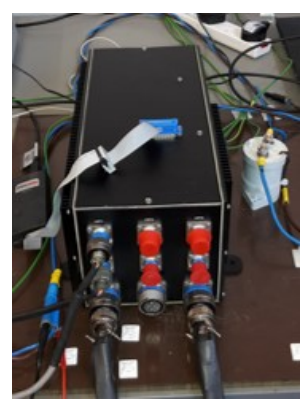

(b) ACE 3D prototype.
Fig. 5: Power Electronics module model and prototype.

high level computation, signal post-processing, control loop calculation; hardware trips and gate drive signal computation are tasks allocated to the FPGA unit. The conventional inverter structure is considered for all the three-phase IGBT power electronics converters. Particular attention is dedicated to the integration of the three converter and control units in a single package. The heat loss dissipation is managed by means of a finned heat sink directly mounted to the power modules as presented in Fig. 5a. The power electronics specification and main parameters are reported in TABLE III and the prototype module is depicted in Fig. $5 b$.

\section{PROTOTYPING}

The designed components are prototyped to demonstrate the functionality of the system. The validation of the system is achieved by means of manufacturing and testing of the single components of the system against a consistent set of specifications. The electrical machines, power electronic, control system and mechanical actuator have been manufactured targeting the final integration. The HEMAS motor laminations have been stacked after being laser-cut and vacuum varnished with EPX50. The winding structure has been manufactured and thermistors were then attached with thermal paste. The varnished stator have been heat-shrink fitted into the anodised AL3043 casing. The fins have been machined into a customised arrangement in order to package the motor tightly into the actuator mechanical structure to reduce system mass and volume. The rotor assembly has been manufactured and balanced to $G 2.5$ according to the standard for rotor balancing [12]. Particular attention is dedicated to the rotor assembly into the machine in order to minimise the risk of shaft bending, due to narrow clearances and slender features. Finally, the end cap with the dedicated connectors is assembled. The ACE unit are assembled in a single box consisting of FPGA-DSP board, three power converter and sensor signal acquisition and elaboration board. The PCB for the power converter gate drives,
TABLE III: Power Electronic parameters

\begin{tabular}{ll}
\hline \hline Parameter & \multicolumn{1}{c}{ Value } \\
\hline \multicolumn{1}{c}{ Power electronics characteristic } \\
Power rating & $2.75[\mathrm{~kW}]$ \\
Peak Current & $35[\mathrm{~A}]$ \\
DC-link voltage & $270[\mathrm{~V}]$ \\
Max supply frequency & $400[\mathrm{~Hz}]$ \\
Inverter switching frequency & $10[\mathrm{kHz}]$ \\
Efficiency & $95[\%]$ \\
\hline
\end{tabular}

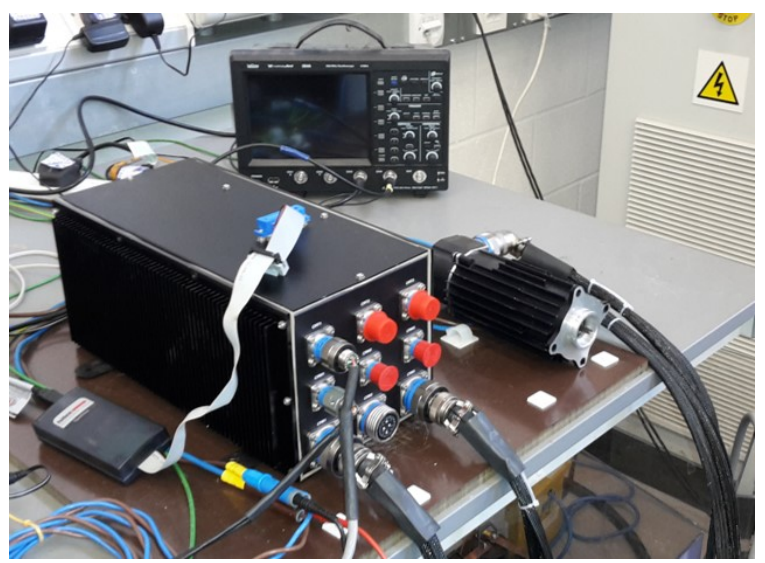

Fig. 6: HEMAS drive system: power electronics module connected to the electrical machine for testing.

the current sensors and the resolver A2D circuit are vertically stacked and attached to the box side. The power modules are directly attached to the casing finned wall which operates as heat sink. In Fig. 6 the electrical machines connected to the power electronics modules are presented.

\section{TESTING AND INTEGRATION.}

The main functionalities of the electrical machines and the power electronics have been tested separately. Furthermore, the capability of the drive system has been tested connecting the electrical machines to an experimental test rig and controlled by means of the ACE power modules.

\section{A. HEMAS electrical machines performances.}

The HEMAS motors have been tested for their capabilities. The validation of the main design characteristics as voltage coefficient $\kappa_{E}[\mathrm{~V} / \mathrm{rpm}]$, torque coefficient $\kappa_{T}[\mathrm{Nm} / \mathrm{A}]$, braking torque and short circuit current have been performed. The testing presented in this section were performed by means of controlling the HEMAS motor with the designed dedicated PE. This was considered the first integration step for the overall system as testing the functionalities of the HEMAS components working together. The resolver signal quality, current controller performances and stability impact the quality of the sub-system output.

1) No Load test: The no load voltage at the terminal of each phase groups is measured and the results are compared with the FE predicted waveforms. In Fig. 7a the time-waveforms are compared and good match between the predictions and the measurements is shown. Furthermore, the fundamental of the no load voltage at the terminal is measured and computed in 


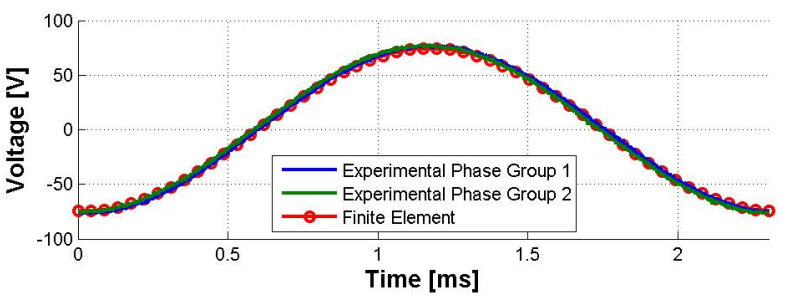

(a) BEMF waveform comparison at $4800 \mathrm{rpm}$.

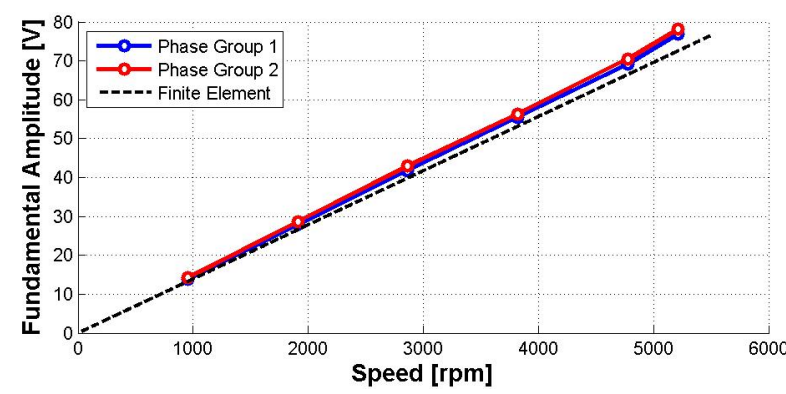

(b) Experimental $\kappa_{E}$ validation.

Fig. 7: No load test results on the electrical machine.

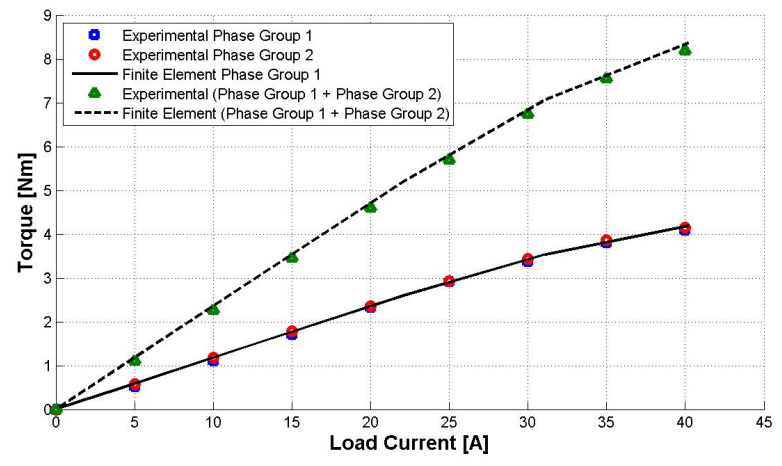

Fig. 8: Load test results on the electrical machine.

the operative speed range of the machine and the results are presented in Fig. 7b, which validate the predicted $\kappa_{E}$ factor.

2) Load test: The torque constant $\kappa_{T}$ is predicted by means of FE simulations. The prototyped electrical machines were coupled with a load machine in order to test their torque capabilities. The ACE power converters were adopted to drive the HEMAS motor and the measured torque characteristic is presented in Fig. 8.

Only $q$-axis current is supplied to each phase group. The latter were tested separately in the first instance. The total torque developed in the case of both phase groups being operative was validated and compared with the FE prediction. The saturation of the soft ferromagnetic cores impact on the developed torque for load current $>30[A]$ and therefore the torque factor $\kappa_{T}$ can be considered constant in the entire operative range of the machine [13].

3) Fault tolerance capabilities.: The fault tolerance capabilities of the electrical machines are considered at the design stage. The double three-phase winding system is chosen in order to guarantee the safe operation of the actuator in case of electrical faults in the machine. Balanced three-phase

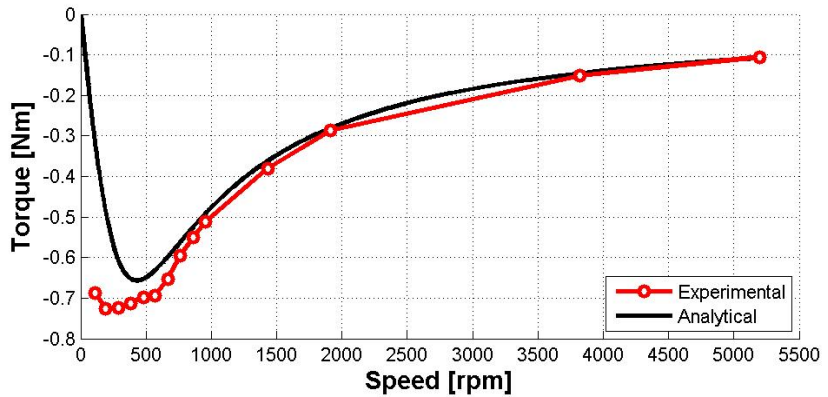

Fig. 9: Short circuit test: analytical and experimental braking torque.

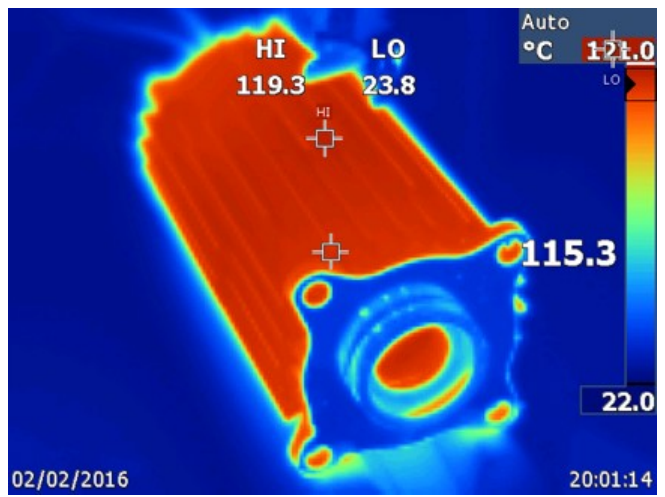

Fig. 10: Electrical machine temperature distribution at rated DC current $|I|=4.7[A]$ and ambient temperature of $T_{a m b}=100\left[{ }^{\circ} \mathrm{C}\right]$.

terminal short circuit enables to induce in the winding system a balanced set of currents, therefore reducing the impact of unbalanced air gap magnetic field which would occur in phasephase or phase-ground electrical fault. The torque generate by the three-phase short circuit current can be predicted according to (1) [14]

$$
T_{s c}=-\frac{3}{2} p \varphi_{0, d}^{2} R_{p h} \omega_{e}\left[\frac{R_{p h}^{2}+\omega_{e}^{2} L_{q}^{2}}{\left(R_{p h}^{2}+\omega_{e}^{2} L_{q} L_{d}\right)^{2}}\right]
$$

where $p$ is the number of pole pairs, $\varphi_{0, d}$ is the no load $d$-axis flux linkage, $R_{p h}$ is the phase resistance, $\omega_{e}$ is the electrical angular speed, $L_{d}$ and $L_{q}$ are the $d$-axis and $q$-axis inductance, respectively. The comparison of the predicted braking torque and the measured values is presented in Fig. 9, showing good agreement.

4) Thermal validation : In order to validate the performance in the challenging environment, the motors were tested in a temperature controlled environmental chamber. The steady-state temperatures at the housing and windings were measured. Ambient temperature of $T_{a m b}=100\left[{ }^{\circ} \mathrm{C}\right]$ have been tested at. The machine is loaded by means imposing the rated DC current and the temperature distribution is presented in Fig. 10. Furthermore, the drive system is tested at ambient temperature of $T_{a m b}=20\left[{ }^{\circ} \mathrm{C}\right]$ imposing the load torque profile to the system. The winding temperature of the electrical machine and the temperatures of individual components of 


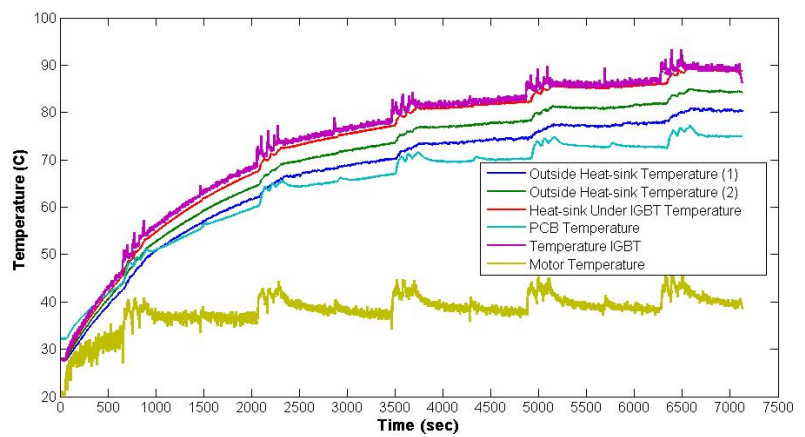

Fig. 11: ACE and electrical machines temperatures profile for operative load-cycle.

the power electronics system have been monitored and are presented in the chart Fig. 11. It is seen that the temperature is mainly affected by the constant load components, whilst the peaks affect the local temperature transients. The results validate the thermal design of the motor demonstrate their suitability for operating within the harsh environment within the helicopter engine and swash-plate enclosure.

5) Rotor-dynamic validation: The rotor-dynamic analysis of the rotor design on the electrical machine have been validated through experimental tests.

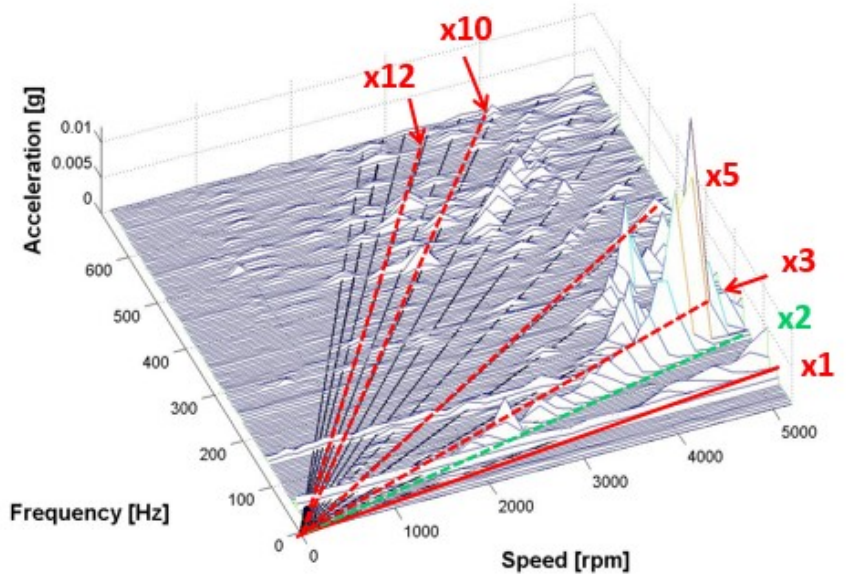

Fig. 12: Experimental vibration measurement on the prototype machine within the operative range at rated torque.

In Fig. 12, the waterfall plot of the vibration level measured at different rotating speed is presented. The vibration measurements are presented in the condition of rated torque developed by the machine. In the chart the main vibrations modes are highlighted and the main components of the vibration multiples are labelled. The machine presents a smooth operative range. Approaching the maximum operating speed, the vibrations tends to become more significant, however, they below critical values. The machine is mainly operated in the range $\omega_{m}=1500[\mathrm{rpm}]$ while the top speed is achieved only for limited amount of time.

\section{CONCLUSION}

The analyses and testing of the main electrical components of an electromechanical helicopter actuation system have been presented. The prototyped electrical machines and power electronics are individually tested and the overall drive performance are assessed. Experimental validation of the electromagnetic, thermal and rotor-dynamic performances are presented.

\section{ACKNOWLEDGEMENT}

This work was supported by the "EU FP7 funding via the Clean Sky JTI Systems for Green Operation ITD".

\section{REFERENCES}

[1] R. Jones, "The more electric aircraft: assessing the benefits," Proceedings of the Institution of Mechanical Engineers, Part G: Journal of Aerospace Engineering, vol. 216, no. 5, pp. 259-269, 2002.

[2] I. Chakraborty, D. N. Mavris, M. Emeneth, and A. Schneegans, "An integrated approach to vehicle and subsystem sizing and analysis for novel subsystem architectures," Proceedings of the Institution of Mechanical Engineers, Part G: Journal of Aerospace Engineering, vol. 230, no. 3, pp. 496-514, 2016.

[3] M. Mulder, B. Lubbers, P. Zaal, M. Van Paassen, and J. Mulder, "Aerodynamic hinge moment coefficient estimation using automatic flyby-wire control inputs," in Proc. of the AIAA Modelling and Simulation Technologies Conference, 2009.

[4] M. Christmann, S. Seemann, and P. Jänker, "Innovative approaches to electromechanical flight control actuators and systems," Recent Advances in Aerospace Actuation Systems and Components, pp. 17-23, 2010.

[5] M. Rottach, C. Gerada, and P. Wheeler, "Design optimisation of a faulttolerant pm motor drive for an aerospace actuation application," 2014.

[6] R. Seresinhe and C. Lawson, "Electrical load-sizing methodology to aid conceptual and preliminary design of large commercial aircraft," Proceedings of the Institution of Mechanical Engineers, Part G: Journal of Aerospace Engineering, vol. 229, no. 3, pp. 445-466, 2015.

[7] G. Fabri, F. Parasiliti, M. Tursini, M. Villani, and L. Castellini, "Pm brushless motor for helicopters electric tail rotor drive system," in Electric Machines and Drives Conference (IEMDC), 2017 IEEE International. IEEE, 2017, pp. 1-7.

[8] W. Cao, B. C. Mecrow, G. J. Atkinson, J. W. Bennett, and D. J. Atkinson, "Overview of electric motor technologies used for more electric aircraft (mea)," IEEE Transactions on Industrial Electronics, vol. 59, no. 9, pp. 3523-3531, 2012.

[9] M. Rottach, C. Gerada, T. Hamiti, and P. Wheeler, "A computationally efficient design procedure for actuator motors using magnetic reluctanceand thermal resistance network models," in Electrical Machines (ICEM), 2012 XXth International Conference on. IEEE, 2012, pp. 2526-2532.

[10] C. xiong Pan, J. zhou Zhang, L. feng Ren, and Y. Shan, "Effects of rotor downwash on exhaust plume flow and helicopter infrared signature," Applied Thermal Engineering, vol. 65, no. 1, pp. 135 - 149, 2014.

[11] A. G. Sarigiannidis, M. E. Beniakar, P. E. Kakosimos, A. G. Kladas, L. Papini, and C. Gerada, "Fault tolerant design of fractional slot winding permanent magnet aerospace actuator," IEEE Transactions on Transportation Electrification, vol. 2, no. 3, pp. 380-390, Sept 2016.

[12] Balance Quality Requirements of Rigid Rotors, ISO 1940-1, International Organization for Standardization International Organization for Standardization ISO 1940-1, Rev. ISO 1940-1, 2003.

[13] L. Papini, C. Gerada, and A. Goodman, "Analysis of a closed-slot pm machine," in 2013 International Electric Machines Drives Conference, May 2013, pp. 578-585.

[14] L. Papini, T. Raminosoa, D. Gerada, and C. Gerada, "A high-speed permanent-magnet machine for fault-tolerant drivetrains," IEEE Transactions on Industrial Electronics, vol. 61, no. 6, pp. 3071-3080, June 2014. 